\title{
Effects of Grain Size and Specimen Thickness on Mechanical Properties of Polycrystalline Copper and Copper-Aluminum Alloy
}

\author{
By Shuichi Miyazaki* and Hiroshi Fujita**
}

\begin{abstract}
Mechanical properties of polycrystalline copper and $\mathrm{Cu}-13$ at $\% \mathrm{Al}$ alloy have been investigated as a function of grain size and specimen thickness at room temperature, with the following results: (1) The flow stress of both copper and $\mathrm{Cu}-13$ at $\% \mathrm{Al}$ alloy decreases as the ratio of specimen thickness to grain size decreases below a critical value. (2) The Hall-Petch relation against the grain size shows a turning point corresponding to the critical value. (3) The Hall-Petch relation is always satisfied in the thick specimens of $\mathrm{Cu}-13$ at \% Al alloy. In thick specimens of copper, however, the grain size in the Hall-Petch relation is replaced by the mean free path of dislocations at various strains. (4) The mean free path of dislocations in copper corresponds to the length of slip bands instead of the cell size, because the cell structure does not develop sufficiently.
\end{abstract}

(Received April 27, 1978)

\section{Introduction}

It has been shown that the strength of polycrystalline aggregates depends on the average grain diameter $(D)$ as shown by the following Hall-Petch relation ${ }^{(1)(2)}$ :

$$
\sigma_{y}\left(\text { or } \sigma_{f}\right)=\sigma_{0}+K \cdot D^{-1 / 2},
$$

where $\sigma_{y}$ is the apparent yield stress, $\sigma_{f}$ the flow stress, and both $\sigma_{0}$ and $\boldsymbol{K}$ empirical factors determined by the specimen and deformation conditions. Equation (1) has been applied not only to the apparent yield stress but to the flow stress ${ }^{(3) \sim(6)}$. However, many controversy points of eq. (1) on the flow stress have been pointed out with the progress in the precision of measurements ${ }^{(7) \sim(9)}$. The most important point is that the value of $D$ in eq. (1) must be replaced by the mean free path of dislocations which is determined by the distribution of obstacles developed during deformation $^{(8)}$. The mean free path of dislocations in metals with high stacking fault energies is determined with the cell walls at considerably high strains ${ }^{(8)}$. Determination

* Graduate School, Osaka University, Suita 565, Japan.

** Department of Materials Science and Engineering, Faculty of Engineering, Osaka University, Yamada-Kami, Suita, Osaka 565, Japan.

Trans. JIM of the mean free path becomes difficult as the stacking fault energy decreases as in a case of copper, because the cell walls do not develop sufficiently in these metals and alloys.

There is another important factor controlling the strength of polycrystals, i.e., the three dimensional stress caused by the interaction with the surrounding grains ${ }^{(10) \sim(13)}$. Both the slip mode and the flow stress are strongly affected by this factor ${ }^{(14)(15)}$. Since eq. (1) should be discussed originally under a fixed boundary condition in which the slip mode is the same, it is very important to investigate the effect of the three dimensional stress on the slip mode.

From this point of view, the present work has been carried out to examine the effect of grain size on the deformation mechanism of polycrystals of copper and $\mathrm{Cu}-13$ at $\% \mathrm{Al}$ alloy as a function of the mean free path of dislocations and the slip mode.

\section{Specimens and Experimental Procedures}

The specimens used were copper and $\mathrm{Cu}-$ 13 at $\% \mathrm{Al}$ alloy which were made from $99.99 \%$ purity copper and $99.99 \%$ purity aluminum. These specimens were heavily cross-rolled at room temperature and followed by annealing in order to avoid the rolling texture.

1978 Vol. 19 
The grain size of these specimens were controlled from 10 to $400 \mu \mathrm{m}$. The grain size was determined by the intersept method. Tensile testing was carried out with a Shimadzu Instron-type Autograph IS-5000 with a constant crosshead velocity of $0.5 \mathrm{~mm} / \mathrm{min}$ at room temperature. Specimens used for tensile testing were plates, whose shoulders have a radius of curvature of $37.5 \mathrm{~mm}$, with the gauge lengths of 15 and $12 \mathrm{~mm}$, respectively. The specimen thickness were varied from 0.13 to $1.84 \mathrm{~mm}$ for each individual grain size in order to investigate the effect of the specimen thickness on the flow stress.

Slip mode and the mean free path of dislocations in the specimens have been determined by both optical and electron microscopy. A Hitachi HU-11D electron microscope operating at $100 \mathrm{kV}$ was used.

\section{Results and Discussion}

\section{Thickness effect on flow stress}

Figure 1 shows the relationship between the flow stress at $20 \%$ strain and the specimen thickness in copper with various grain sizes. The ordinate represents the flow stresses at $20 \%$ strain which are normalized by the flow stress of the sufficiently thick specimens, and the abscissa the ratio of the specimen thickness $(t)$ to the grain size $(d)$. It is apparent from this figure that the flow stress decreases with

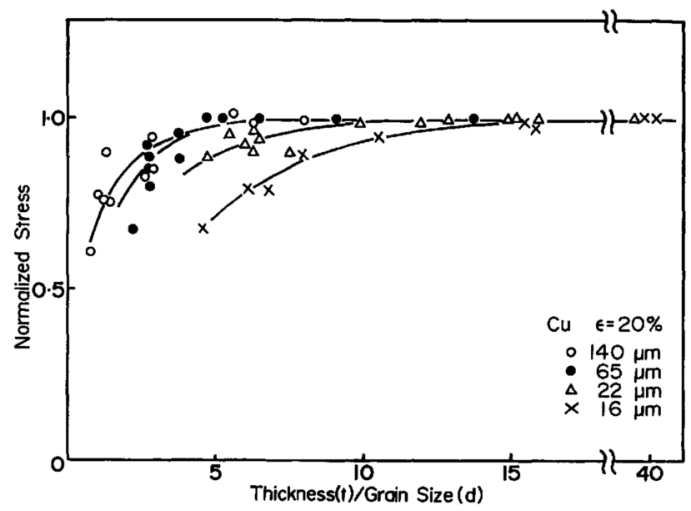

Fig. 1 Thickness effect on the flow stress at $20 \%$ strain in polycrystalline copper with various grain sizes. decreasing value of $t / d$ when the value of $t / d$ is smaller than a critical one. The critical value of $t / d$ depends on the grain size, i.e., it is about 5 for a large grain size (65 and $140 \mu \mathrm{m}$ ) and about 12 for a grain size of $16 \mu \mathrm{m}$.

The effect of specimen thickness also appears in $\mathrm{Cu}-13$ at \% Al alloy. Figure 2 shows the relation between the flow stresses at $20 \%$ strain and the specimen thickness in $\mathrm{Cu}-$ 13 at $\% \mathrm{Al}$ alloy. The critical value of $t / d$ also decreases with decreasing grain size in $\mathrm{Cu}-13$ at \% Al alloy; for example, it is about 20 for a grain size of $31 \mu \mathrm{m}$ and about 5 for $77 \mu \mathrm{m}$.

As mentioned above, the effect of specimen thickness appears in both copper and $\mathrm{Cu}-$ 13 at $\% \mathrm{Al}$ alloy, and the critical value of $t / d$ depends not only on the grain size but also on the stacking fault energy. In order to understand the cause of this effect, the dislocation structures at $20 \%$ strain have been observed in $\mathrm{Cu}-13$ at $\% \mathrm{Al}$ alloy with different grain sizes, as shown in Photo. 1. Grain sizes of the specimens in Photo. 1(a) and (b) are 100 and $10 \mu \mathrm{m}$, respectively. In these micrographs, the dislocations of many slip systems are activated and homogeneously distributed in the small grains compared with those in the large ones. This suggests that the small grain is strongly affected by its surrounding grains more than the large one so that the critical value of $t / d$ increases with decreasing grain size.

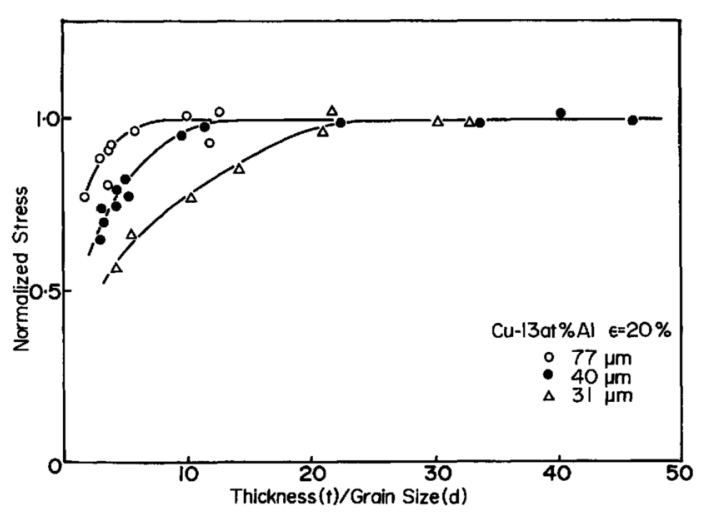

Fig. 2 Thickness effect on the flow stress at $20 \%$ strain in polycrystalline $\mathrm{Cu}-13$ at $\% \mathrm{Al}$ alloy with various grain sizes. 


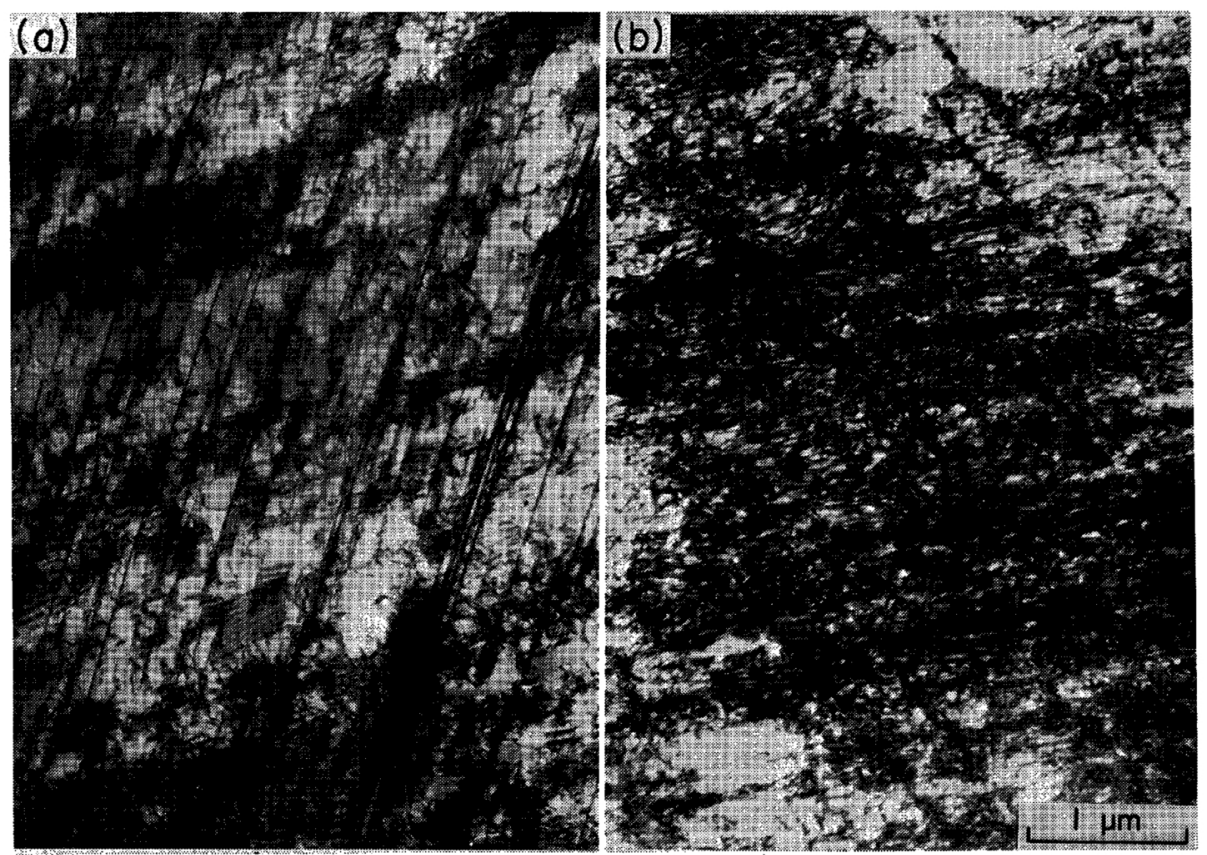

Photo. 1 Effect of grain size on dislocation structures in polycrystalline $\mathrm{Cu}-13$ at $\% \mathrm{Al}$ alloy deformed to $20 \%$ strain. Grain size: (a) $100 \mu \mathrm{m}$, (b) $10 \mu \mathrm{m}$.

\section{Grain size dependence of the flow stress}

Figure 3 shows relations between the flow stress at various strains and the grain size in copper. It should be noted that the flow stress cannot be expressed by a simple linear relation against the inverse square root of grain size. The specimen thickness used is $0.2,0.5$ and $1.0 \mathrm{~mm}$, respectively. In the specimens $0.2 \mathrm{~mm}$ thick, the linear relation is turned down at a point where the grain size is $16 \mu \mathrm{m}$ and the corresponding value of $t / d$ is about 12. This is due to the thickness effect on the flow stress as shown in Fig. 1. Similarly, in both specimens 0.5 and $1.0 \mathrm{~mm}$ thick, this kind of turning point is also expected to appear when the grain sizes are 100 and $200 \mu \mathrm{m}$, respectively, whose corresponding value of $t / d$ is 5 , though it is not clear practically because accurate measurement of the flow stress becomes difficult in the region of large grain sizes.

Another kind of turning point also appears in Fig. 3, as indicated by a dotted line. This turning point always appears at the same grain size of about $60 \mu \mathrm{m}$ in all specimens.

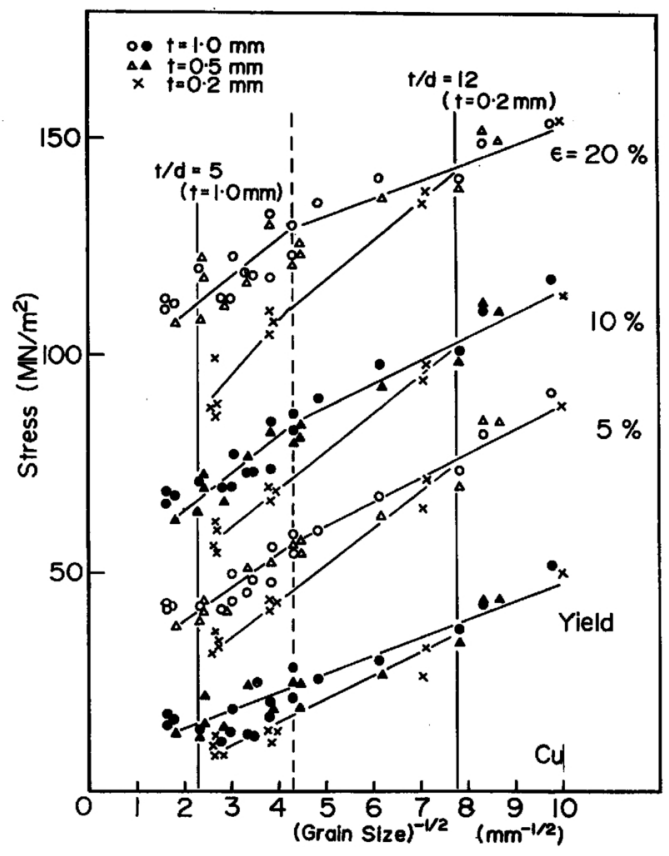

Fig. 3 Relation between the flow stress and the inverse square root of grain size in polycrystalline copper.

In specimens of 0.5 and $1.0 \mathrm{~mm}$ thick, the turning point sharply appears as the strain 


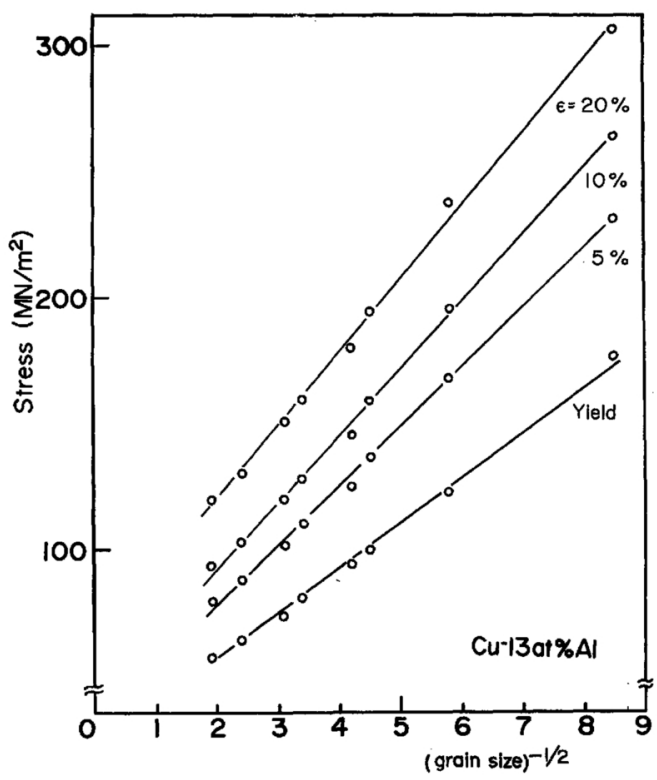

Fig. 4 Relation between the flow stress and the inverse square root of grain size in polycrystalline $\mathrm{Cu}-13$ at \% Al alloy.

increases, but it is only observed at $20 \%$ strain when the specimen thickness decreases to $0.2 \mathrm{~mm}$.

Figure 4 shows the Hall-Petch relation of the flow stress in $\mathrm{Cu}-13$ at $\% \mathrm{Al}$ alloy. In this case, the flow stress can be always expressed by a linear relation with the grain size.

As mentioned above, there are many differences in the flow stress vs grain size relation between copper and $\mathrm{Cu}-13$ at $\% \mathrm{Al}$ alloy. These differences are considered to result from the difference of slip mode in both specimens.

\section{Slip band formation at various stages of deformation}

Photograph 2 shows the configuration of slip bands at various stages of deformation in copper. Each micrograph was taken after electropolishing followed by $1 \%$ elongation when the same specimen is deformed to various strains indicated in micrographs respectively. An annealing twin marked with an arrow is the marker indicating a fixed position in the specimen. It is to be noted in Photo. 2 that the length of slip bands decreases with increasing strain, as recognized by comparing micrographs (a) (d) with each other.

The same observation was also carried out in $\mathrm{Cu}-13$ at $\% \mathrm{Al}$ alloy as shown in Photo. 3. In this case, the slip bands are always linear and sufficiently long independently of the strains,
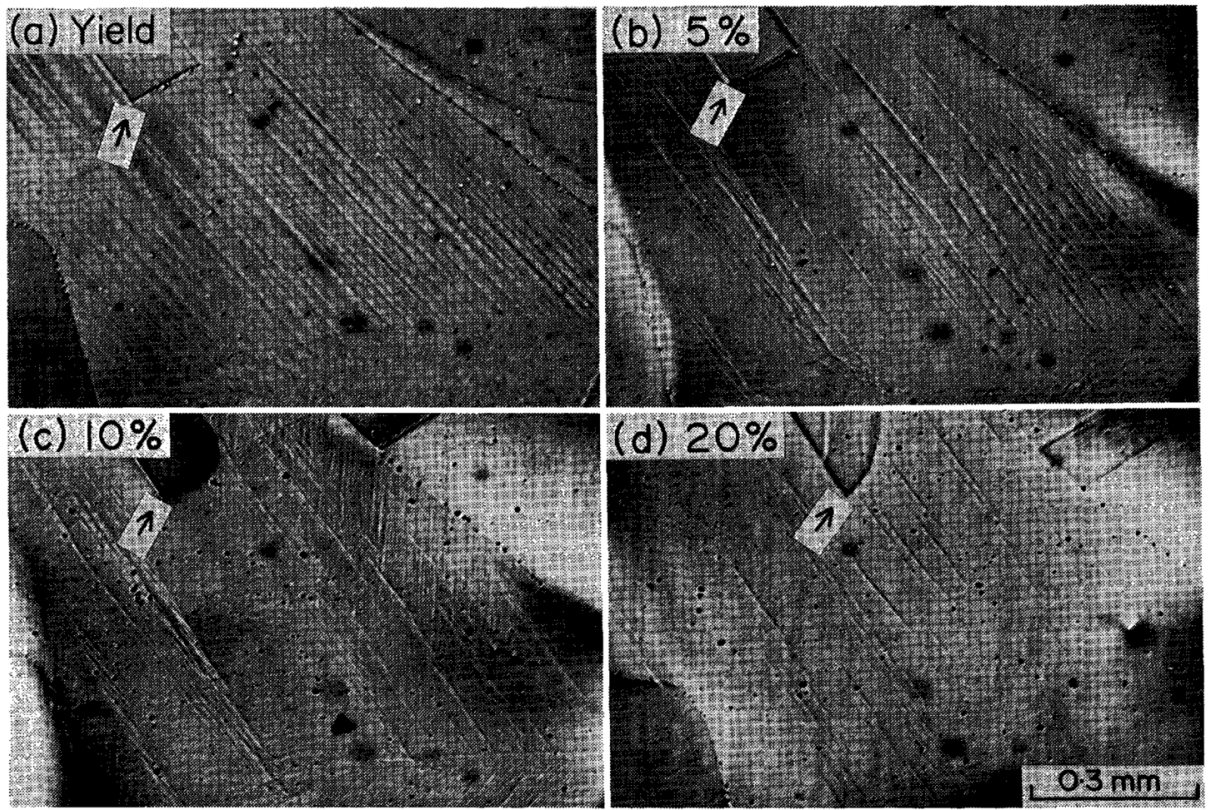

Photo. 2 Configuration of slip bands at various stages of deformation in polycrystalline copper. Each micrograph was taken after electropolishing followed by $1 \%$ elongation. 

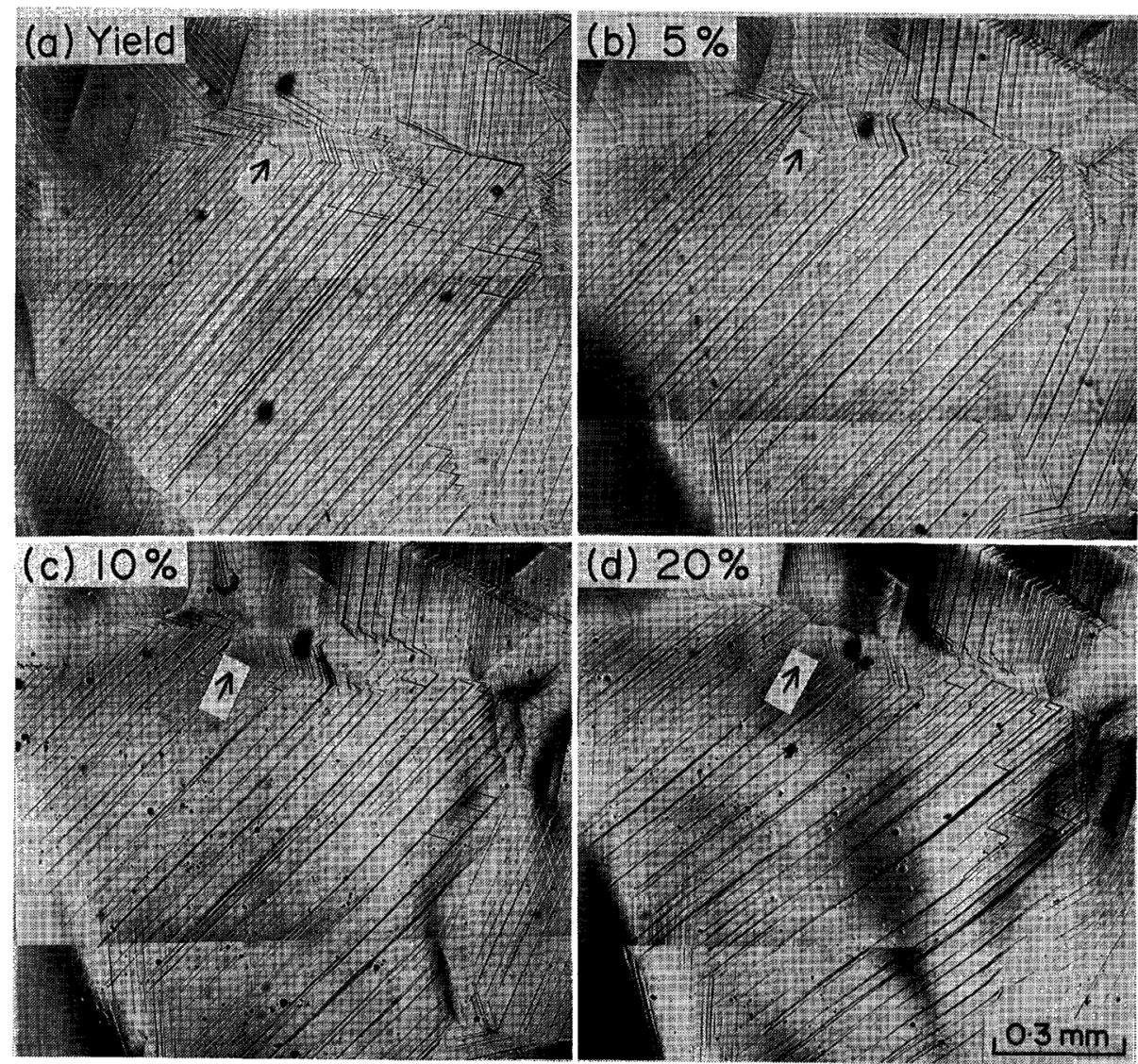

Photo. 3 Configuration of slip bands at various stages of deformation in polycrystalline $\mathrm{Cu}-13$ at \% Al alloy. Each micrograph was taken after electropolishing followed by $1 \%$ elongation.

i.e., the length of them nearly equal to the grain size even when the strain increases up to $20 \%$.

\section{Observation of the dislocation structures}

Photograph 4(a) and (b) are the dislocation structures in copper and $\mathrm{Cu}-13$ at $\% \mathrm{Al}$ alloy deformed to $20 \%$ strain, respectively. In the case of copper, the cell structure is formed, but it is not developed sufficiently even at $20 \%$ strain so that a heterogeneous distribution of the cell walls are observed. In $\mathrm{Cu}-13$ at $\% \mathrm{Al}$ alloy, however, the cell structure is not formed even at $20 \%$ strain, only a planar distribution of the dislocations is observed.

\section{Mean free path of dislocations}

The turning point corresponding to a dotted line in Fig. 3 in the flow stress vs grain size relation was also observed by one of the authors in aluminum ${ }^{(8)}$. In aluminum with a considerably high stacking fault energy, well developed cell structure is formed at $20 \%$ strain, and the cell size corresponds well to the mean free path of dislocations. In this case, the flow stress can be expressed by a simple linear function of the inverse of the cell size ${ }^{(8)}$.

Stacking fault energy of copper, however, is lower than that of aluminum, and thus the cell walls do not develop sufficiently even at $20 \%$ strain, as shown in Photo. 4(a). This means that the cell size does not correspond to the mean free path of dislocations. Therefore, in order to measure the mean free path of dislocations in copper, the length of slip bands at various strains were observed by optical microscopy and electron microscopy using the replica method, respectively. Photograph 5(a) and (b) were taken after electro- 

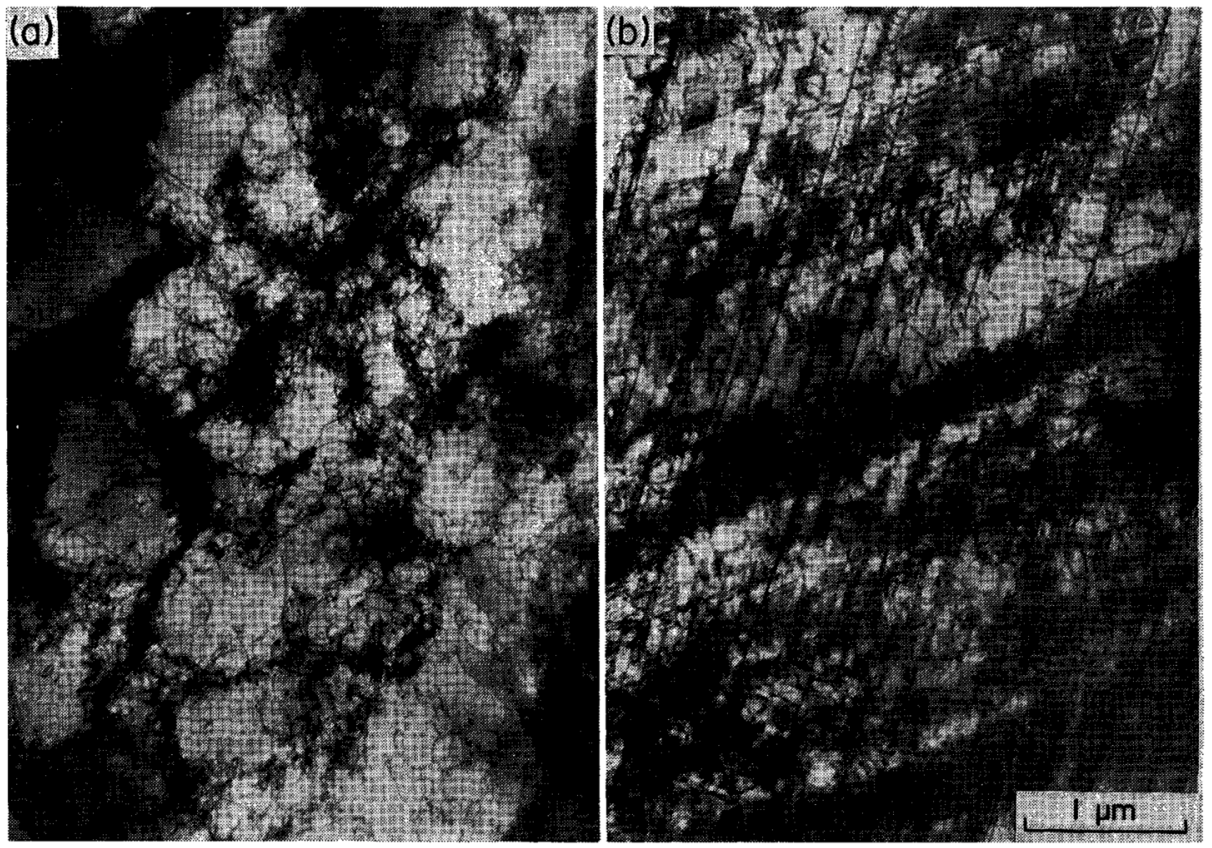

Photo. 4 Dislocation structure in polycrystalline (a) copper and (b) $\mathrm{Cu}-13$ at $\% \mathrm{Al}$ alloy deformed to $20 \%$ strain.
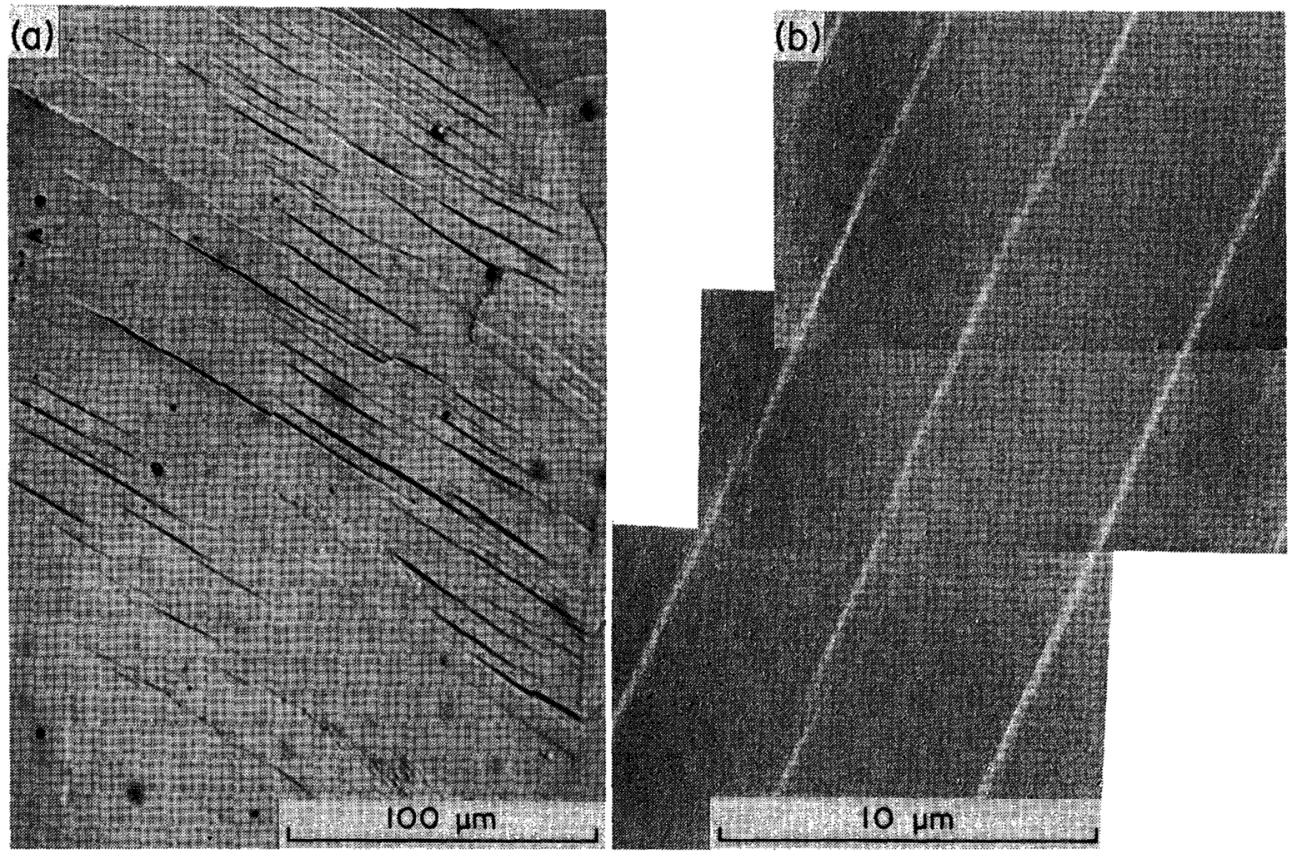

Photo. 5 Distribution of slip bands at $20 \%$ strain in polycrystalline copper observed by (a) optical and (b) replica-electron microscopy.

polishing of about $0.5 \mathrm{~mm}$ thick followed by further $1 \%$ elongation at $20 \%$ strain. Although the cell size in Photo. 4(a) is of the order of
$1 \mu \mathrm{m}$, the length of slip bands is about 10 $\mu \mathrm{m}$ in Photo. 5. This means that only welldeveloped cell walls contribute to determine 


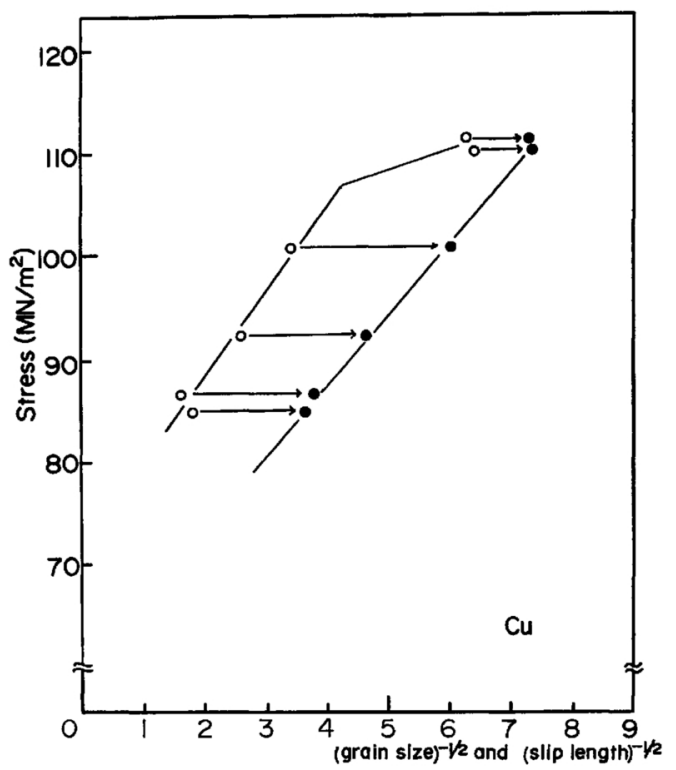

Fig. 5 Relation between the flow stress at $15 \%$ strain and the length of slip bands.

the mean free path of dislocations. Therefore, the flow stresses were analyzed as a function of the length of slip bands as shown in Fig. 5. In this figure, the flow stresses are plotted against the inverse square root of grain size (open circles) and against that of the slip length (closed circles), respectively. It must be noted in Fig. 5 that the relation between the flow stress and the mean free path of dislocations can be expressed by a linear relation even in the case of copper when the mean free path of dislocations is replaced by the length of slip bands.

In the case of $\mathrm{Cu}-13$ at $\% \mathrm{Al}$ alloy with a low stacking fault energy, the length of slip bands is almost the same as the grain size, as seen in Photo. 3, and thus the mean free path of dislocations can be expressed by the grain size, as expected from Fig. 4.

\section{Conclusion}

The results obtained in the present experiment are summarized as follows:

(1) The flow stress decreases as the ratio of the specimen thickness $(t)$ to the grain size (d) decreases when the value of $t / d$ is less than a critical value. The critical value of $t / d$ in- creases with decrease in both grain size and stacking fault energy.

(2) As a result of fact (1), the Hall-Petch relation against the grain size shows a turning point corresponding to the critical value of $t / d$ when the specimen thickness is not so large.

(3) When the stacking fault energy is considerably large as in a case of copper, the flow stress at various strains deviates from the Hall-Petch relation against the grain size even though the specimen thickness is thick enough. They are roughly subdivided into two groups each of which is characterized by a different linear relation.

(4) Grain size in the Hall-Petch relation must be replaced by the mean free path of dislocations in deformed copper as with aluminum. The mean free path of dislocations in copper corresponds to the length of slip bands instead of the cell size, because the cell structure does not develop sufficiently in copper. The flow stresses in the thick specimens can be expressed by a simple linear relation against the inverse square root of the slip length.

(5) The length of slip bands in $\mathrm{Cu}-13$ at $\% \mathrm{Al}$ alloy is almost the same as the grain size nevertheless the strain.

\section{REFERENCES}

(1) E. O. Hall: Proc. Phys. Soc. (London), B64 (1951), 747.

(2) N. J. Petch: J. Iron Steel Inst., 174 (1953), 25.

(3) R. Armstrong, I. Codd, R. M. Douthwaite and N. J. Petch: Phil. Mag., 7 (1962), 45.

(4) J. W. Aldrich and R. W. Armstrong: Met. Trans., 1 (1970), 2547.

(5) R. W. Armstrong: Met. Trans., 1 (1970), 1169.

(6) W. L. Phillips and R. W. Armstrong: Met. Trans., 3 (1972), 2571.

(7) A. W. Thompson, M. I. Baskes and F. Flangan: Acta Met., 21 (1973), 1017.

(8) H. Fujita and T. Tabata: Acta Met., 21 (1973), 355.

(9) T. Tabata, K. Takagi and H. Fujita: Trans. JIM, 16 (1975), 569.

(10) W. T. Pell-Walpole: J. Inst. Metals, 69 (1943), 131.

(11) R. W. Armstrong: J. Met. Phys. Solids, 9 (1961), 196.

(12) R. L. Fleisher and W. H. Hosford, Jr.: Trans. Met. Soc. AIME, 221 (1961), 244.

(13) A. W. Thompson: Scripta Met., 8 (1974), 145.

(14) M. F. Ashby: Phil. Mag., 21 (1970), 399.

(15) T. L. Johnston and C. E. Feltner: Met. Trans., 1 (1970), 1161. 